\title{
A geophysical study of a coastal plane in Sardinia
}

\author{
Gaetano Ranieri, Luciana Ferrero and Alberto Godio \\ Dipartimento di Georisorse e Territorio, Politecnico di Torino, Italy
}

\begin{abstract}
The paper deals with some aspects of the planning and the interpretation of the IP and resistivity measurements in the San Priamo coastal plane (Sardinia, Italy). The plane presents some hydrogeological problems related to previous flowages and salt water intrusion from the sea. The geophysical results verified the good resolution of the joint elaboration of the IP and the resistivity soundings, in order to delineate some hydrogeological aspects of the San Priamo coastal plane. In particular, the technique was suitable for detecting salt water intrusion in a fresh acquifer, with good reliability.
\end{abstract}

Key words induced polarization - salt intension

\section{Introduction}

The San Priamo Valley, in the South-East of Sardinia, just south of the village of Muravera, was formed by the alluvial formation of the Rio Picocca. The region is quite important for agricultural and turistic reasons, but many hydro-geological problems have arisen; during recent years numerous flowages have, infact, occurred, destroying what man had constructed to protect the cultivated areas.

Salt water intrusion in the coastal area of San Priamo represents another important problem. This salt intrusion can be explained by the vicinity of the sea and the agricultural water exploitation.

A geophysical survey has been planned in order to evaluate:

1) the salt water intrusion and the limit between the fresh and the salt groundwater;

2) the existence of sandy-clay levels that could represent the interface between different groundwater levels;

3) the depth and the morphological trend of the crystalline bedrock.
This paper deals with some practical aspects of the planning and interpretation of the IP and resistivity measurements in the investigated area.

The possibility of using induced polarization geoelectrical techniques to individuate saline water intrusion was first investigated by Lazreg (1972). Later, Roy and Elliot (1980) verified that the resistivity method alone is unable to distinguish between freshwater, clays or shales and saline water sand. It was shown that the joint analysis of the IP and the resistivity response can better resolve the stratigraphical ambiguities. It was also concluded that a simultaneous decrease in IP and resistivity response can indicate the saline water intrusion. Barbieri et al. (1986) observed a negative IP response in zones subjected to salt intrusion in sandy formations.

\section{Geological outlines}

The region is mainly formed by Quaternary deposits of the Flumendosa river on a Palaeozoic bedrock. In the San Priamo plane, the crystalline outcrop is on the border of the 
coastal plane and is linked to it by an alluvial belt.

At present, the Rio Picocca is embanked by drainage works and the river meanders between the earliest deposits. The ancient delta embouchures are numerous and not evidently linked to the main watercourse (Montaldo, 1947).

The relief on the north-western side is made up of smooth schistose formations of Palaeozoic and it is deeply marked by watercourses.

On the south-western side the exogenous agents formed more sharp shapes: the aspect is more variegated and the relief reaches $300 \mathrm{~m}$ of altitude.

The alluvial plain is formed by the deposition of detrital materials that have been eroded, transported and deposited by streams. The sediments are mainly composed of sand and fine sandy clay, caused by the loosening and transportation of granitic rock debris.

\section{Geophysical measurements}

The resistivity and induced polarization parameters were evaluated by using data from 19 Vertical Electrical Soundings (VES).

The soundings were carried out as far as was possible along 4 alignments parallel to the sea coast and 4 perpendicular to it (fig. 1). The measurements were obtained using the Schlumberger array with $600 \mathrm{~m}$ as a maximum

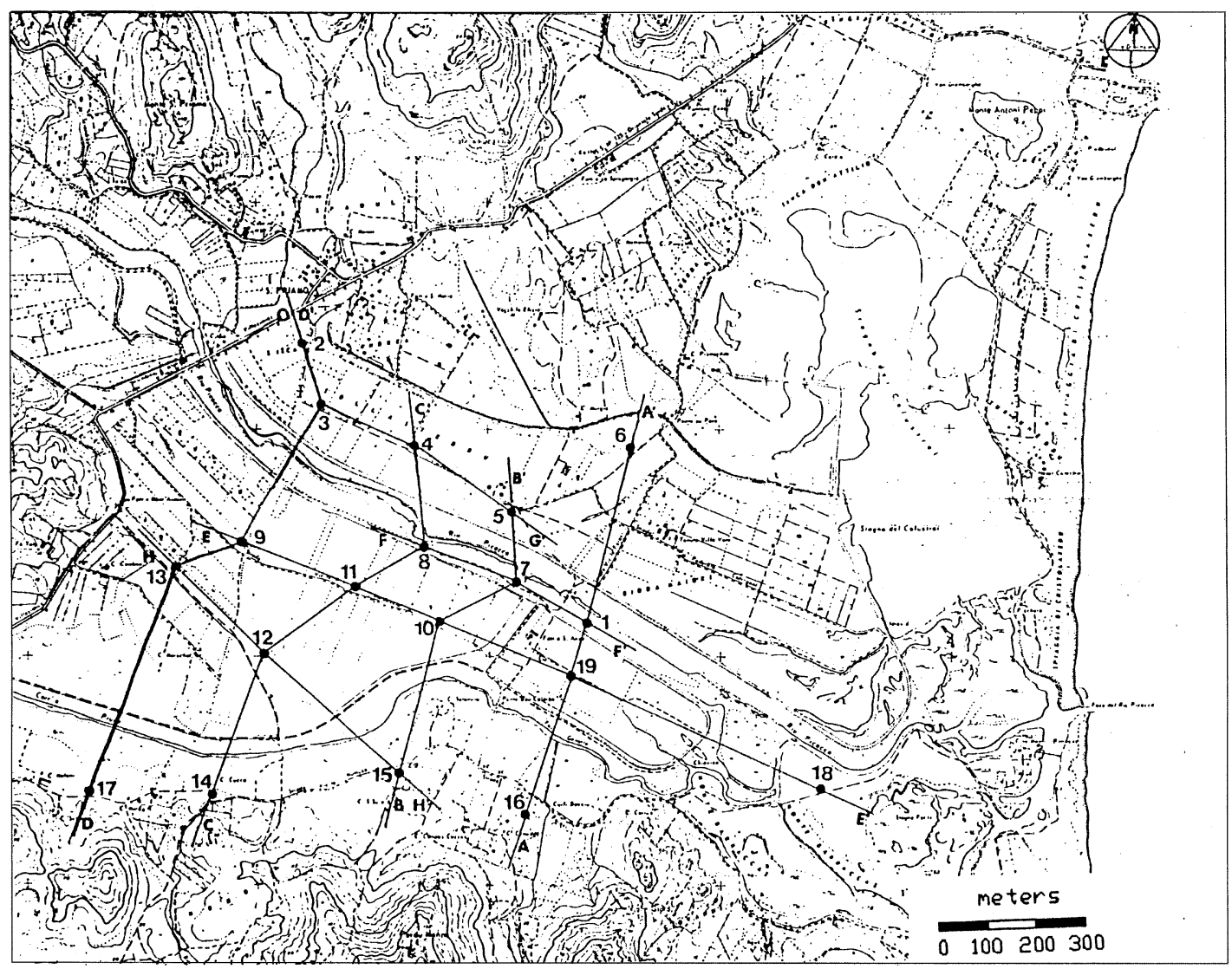

Fig. 1. Topographic map of the investigated area with locations and alignments of the sections used in the 2-D geological interpretation of the electrical soundings. 
AB spread, employing 8 measurements per decade. The same array was used for the evaluation of IP parameters in time domain.

The instrumentation used was:

- a $115 \mathrm{~V}$ generator set, with $400 \mathrm{~Hz}$ frequency and $5 \mathrm{~kW}$ load power;

- an AUSTRAL T-842, T.D. and F.D., transmitter;

- a SCINTREX IPR 10 T.D. receiver with automatic removal of the spontaneous potential and voltage measurement using a $0.1 \mu \mathrm{V}$ sensitivity digital voltmeter .

Two types of problems can occur during data acquisition in sedimentary formations:

1) the presence of a great variability in the IP response, probably correlated to the polarizing phenomena of thin layers at different depths;

2) experimental inaccuracies that affect the apparent chargeability values corresponding to the largest electrodical spreads. High values of standard deviation that refer to the average chargeability values, due to the bad signal/ noise ratio, can be recorded.

Special care was necessary when IP measurements were carried out, especially when soundings were performed in saline sedimentary formations, as the voltage signal was very low. Some check-ups of the capacitive and electromagnetic coupling were performed, in order to reduce the noise effect on the measurements; signal stacking was also carried out to improve the signal/noise ratio at the higher electrode spreads. The IP survey was carried out in time domain: a pulse duration time of $2 \mathrm{~s}$ was chosen, in order to obtain a good compromise between the measurement chargeability stability and the time and cost of the survey.

\section{Elaboration}

First, a qualitative elaboration of the apparent resistivity and chargeability curves was carried out, in order to detect the presence of salt water contamination along the coastal plane. The quantitative elaboration of resistivity data was performed using RESIX Software
(Interpex Ltd). The resistivity elaboration alone was not able to solve between clay, salt and fresh water. The joint inversion of the apparent resistivity and apparent chargeability data was performed to improve the reliability of the interpretation.

\subsection{Soundings in contaminated areas}

Salt and fresh water acquifers in fine sandy formations with different clay content can present the same behaviour as the apparent resistivity curves. Some ambiguities can arise in the quantitative elaboration because the saline acquifer and shale layers can be characterized by similar resistivity values. In some cases, the interpretation of IP data can solve these ambiguities. For instance, the IP response of fine sandy clay layers increases with the content of fine clay materials; shale levels, instead, are usually characterized by a low IP response. The geological features in the investigated alluvial deposit suggest that shale levels are not present in the area. In this case, the IP response becomes a useful tool to distinguish sandy levels with high clay content (low resistivity and high chargeability values) and a saline water acquifer. The presence of saline water intrusion in sandy formations, according to Roy and Elliot (1980), can be indicated by the simultaneous decrease of resistivity and chargeability curves.

Figure 2 shows the results of vertical sounding 16 in the contaminated area; the interpretation of resistivity and chargeability data detects saline contamination. The contaminated sandy layers are located at a depth between $10 \mathrm{~m}$ and $30 \mathrm{~m}$. The same behaviour as the selected example was observed for soundings $1,5,7,8$, 10,11 and 19. It was also observed, in the area potentially affected by the saline intrusion, that negative chargeability values occurred in some soundings. Some ambiguities can arise from the interpretation of such data:

- negative values could be due to electromagnetic coupling effects;

- negative induced polarization effects can also occur if the geoelectric section is of the $K$ 


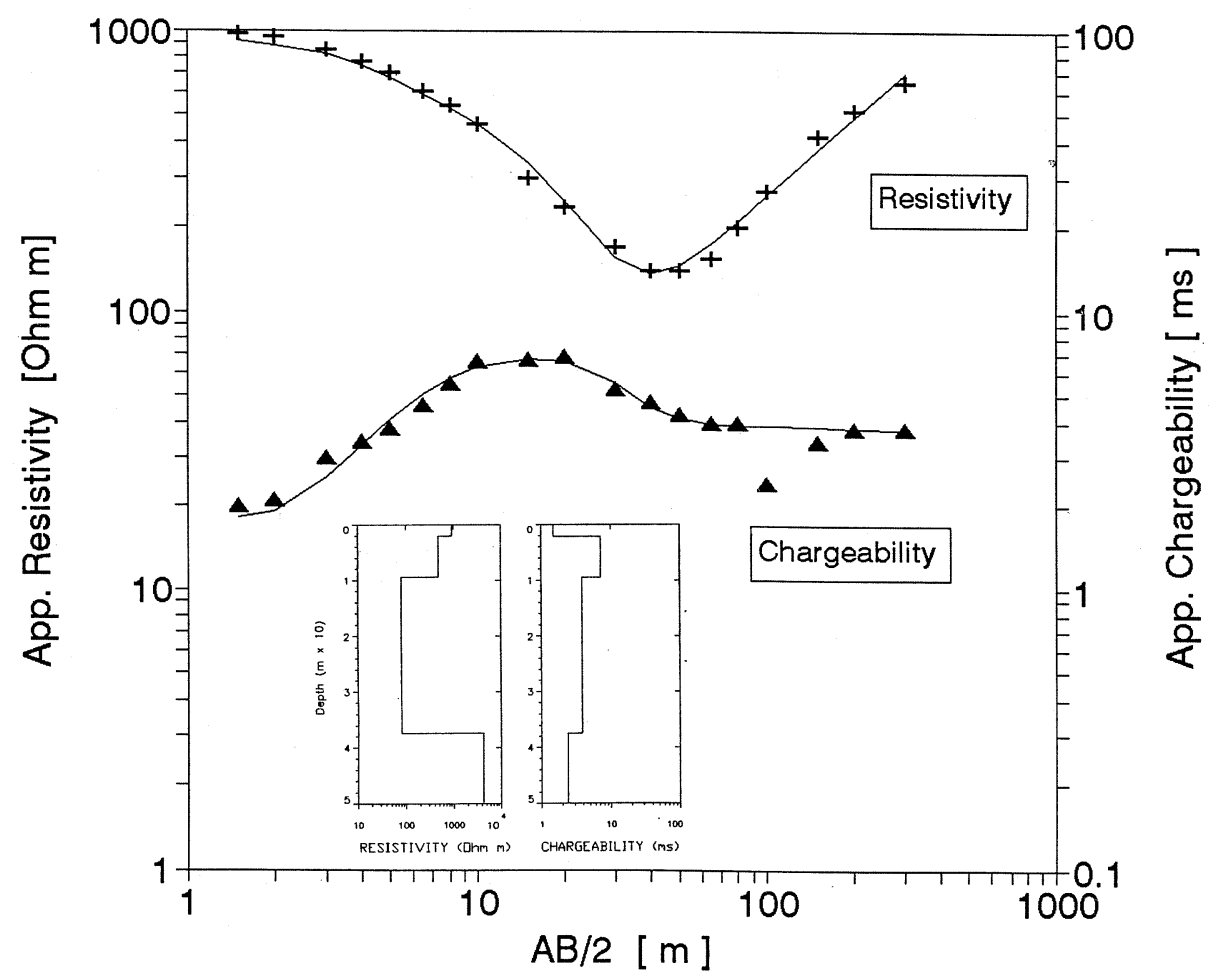

Fig. 2. Example of resistivity and chargeability curves of sounding 16 . The center of the VES was in the contaminated area; the salt water intrusion is indicated by the simultaneous decrease of the two curves.

$(\rho 1<\rho 2>\rho 3)$ or $Q(\rho 1>\rho 2>\rho 3)$ type (Nabighian and Elliot, 1976).

In order to reduce the electromagnetic coupling effect, the survey was carried out in time domain using a very low frequency $(0.125 \mathrm{~Hz})$. The values of the chargeability were computed, considering only the later portion of the decay curve.

The negative effect of the chargeability, corresponding to the curves of the soundings can be explained by the behaviour of the resistivity of the site. According to the theory of Seigel (1959), the apparent IP response $M_{a}$ is defined as the summation of the effects of each layer $\left(M_{j}\right)$ :

$$
M_{a}=\sum_{j=1}^{m} B_{j} \cdot M_{j}
$$

where $m+1$ indicates the number of layers.
The function $B_{j}$ is linked to the resistivity of each layer by the following relationship:

$$
B_{j}=\frac{\partial \log \rho_{a}}{\partial \log \rho_{j}}=\frac{\rho_{j}}{\rho_{a}} \cdot \frac{\partial \rho_{a}}{\partial \rho_{j}}
$$

and $B_{j}$ coefficients must satisfy the relationship (Seigel, 1959):

$$
\sum_{j=1}^{m+1} B_{j}=1 .
$$

For a 4-layer subsoil $(m=3)$, the following equation can be written:

$$
\sum_{j=1}^{4} B_{j}=B_{1}+B_{2}+B_{3}+B_{4}=1 .
$$

For a resistivity section characterized by a $Q H$ 
curve, the coefficient $B_{1}$ is positive for small and large electrode spread while it is negative for intermediate aperture (Nabighian and Elliot, 1976). The coefficients $B_{2}, B_{3}$ and $B_{4}$ are always positive.

As can be seen in fig. 3 the resistivity curve of sounding 7 indicates an electro-stratigraphy of the $Q H$ type: sounding 1 presents a similar response. In these cases, it appears difficult to relate the negative IP response to the saline intrusion.

However, the trend of the chargeability and resistivity curves shows, in a qualitative way, the existence of the saline intrusion.

The response of the soundings 3, 5, 10 and 18 presents some interesting features (figs. 4a-d); negative values of the chargeability were observed for little spread of the current electrodes. The phenomenon cannot be explained by Nabighian and Elliots' theory: the negative values of the chargeability could be diagnostic of a high salinity in the near surface layers. The reliability of the IP response, due to the low voltage signal in the presence of a high conductive layer, can be weak and great care must be taken in interpretation. Figure $4 d$ shows an example of a sounding (18) carried out in an area close to the sea coast; the chargeability curve shows a great variability of values, probably due to the high salinity of the near surface layers where very low resistivity values are expected.

\subsection{Soundings in uncontaminated areas}

The interpretation of the resistivity curves indicates the presence of the crystalline bedrock at a depth variable between $10 \mathrm{~m}$ and $30 \mathrm{~m}$. A joint interpretation of resistivity and

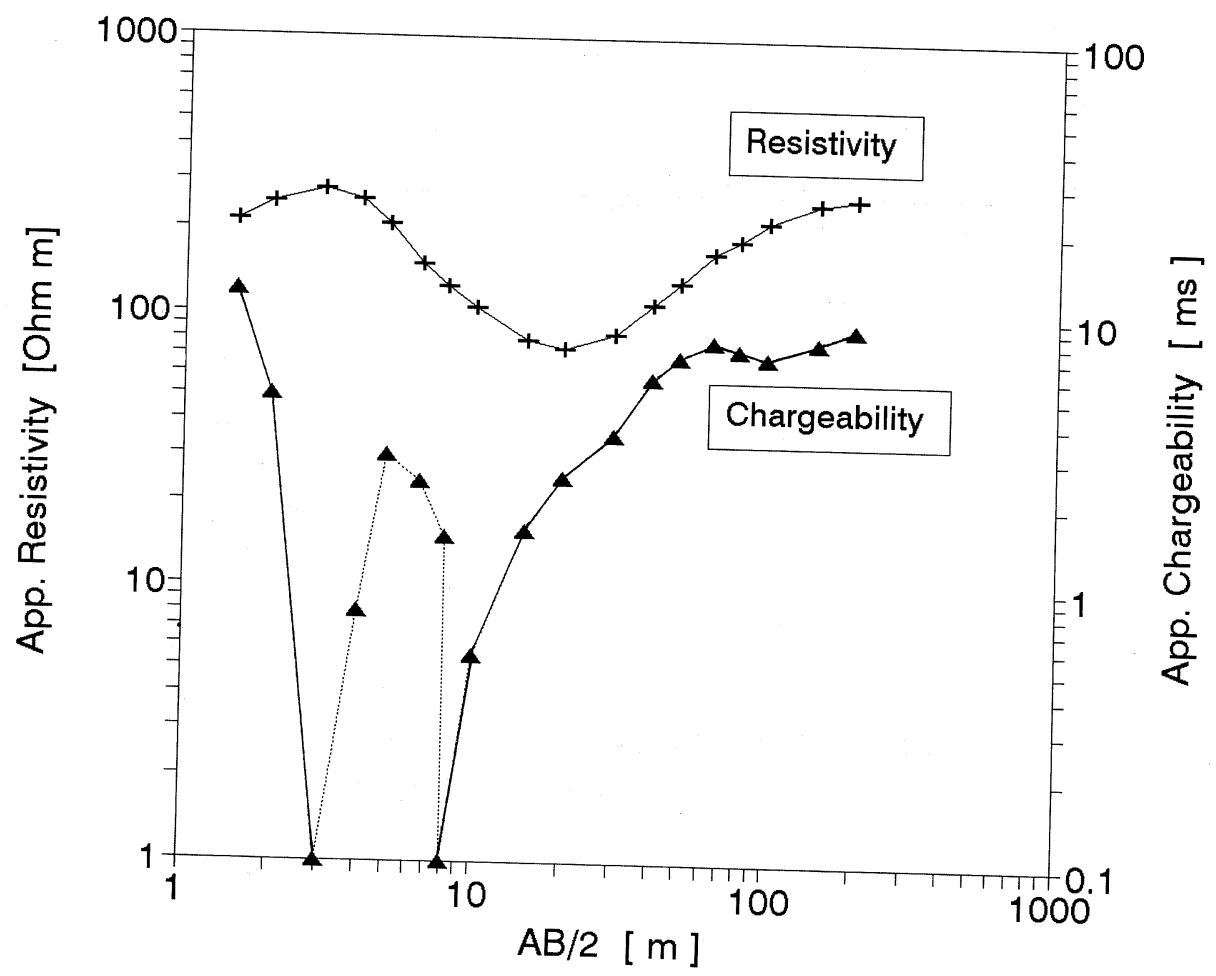
Fig. 3. Example of the negative response of the chargeability curve in the contaminated area (VES 7). The
dotted line indicates the negative chargeability values on the log-log plot. 

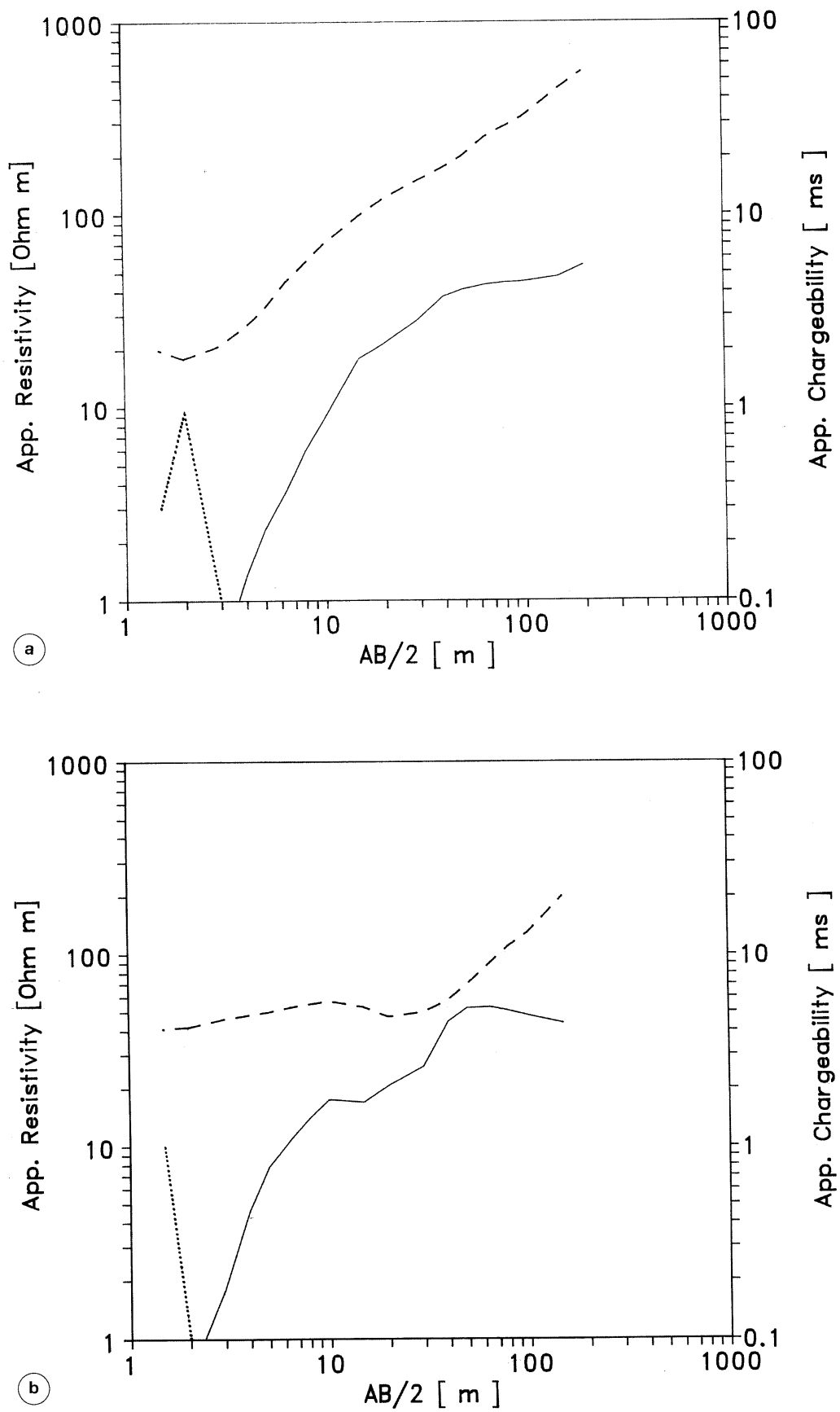

Fig. 4a,b. Apparent resistivity (dashed lines) and chargeability curves (continuous lines) for soundings 3 (a) and 5 (b) in the area contaminated by the near surface salt water intrusion. Dotted lines indicate negative values of apparent chargeability. 

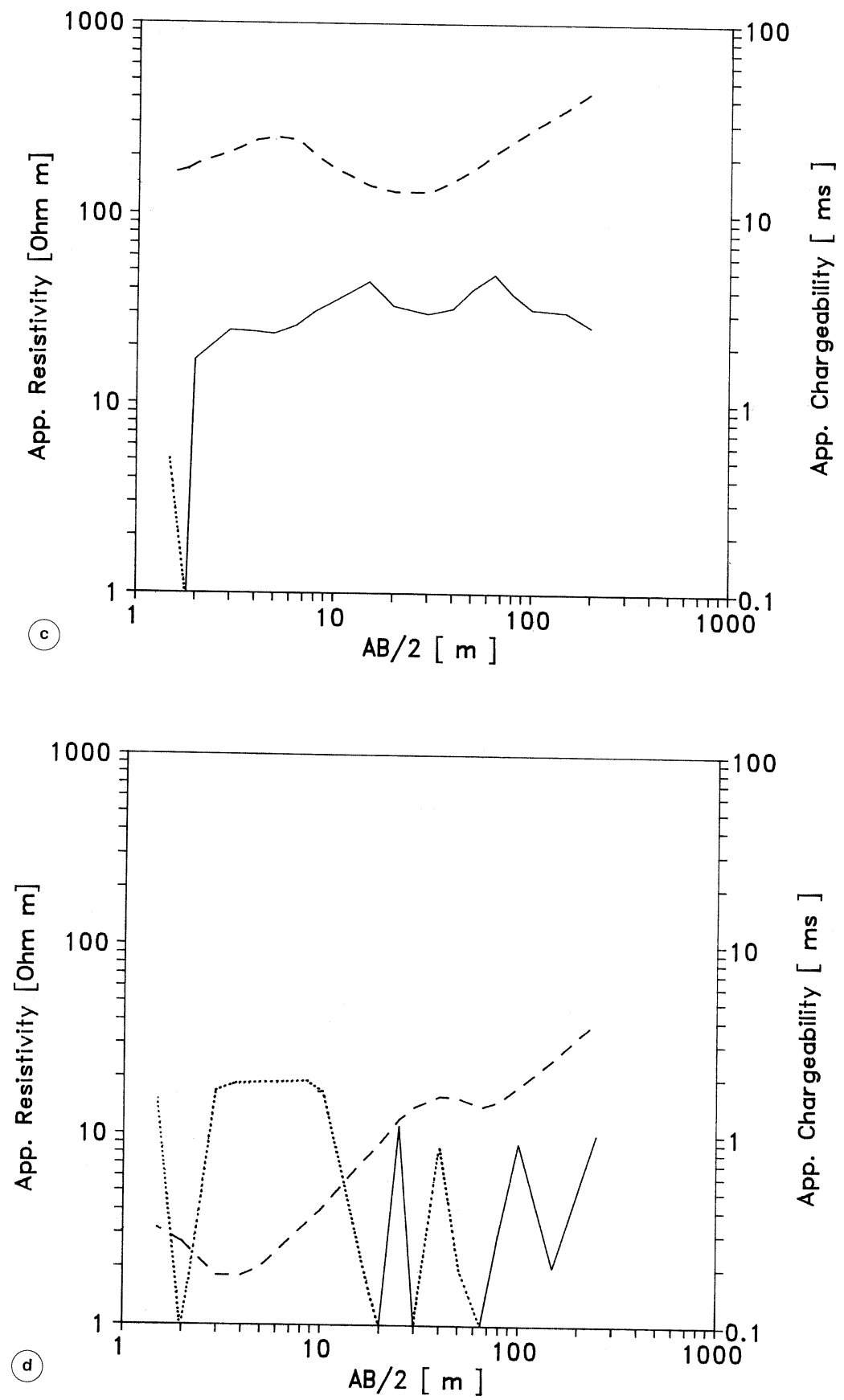

Fig. 4c,d. Apparent resistivity (dashed lines) and chargeability curves (continuous lines) for soundings 10 (c) and 18 (d) in the area contaminated by the near surface salt water intrusion. Dotted lines indicate negative values of apparent chargeability. 


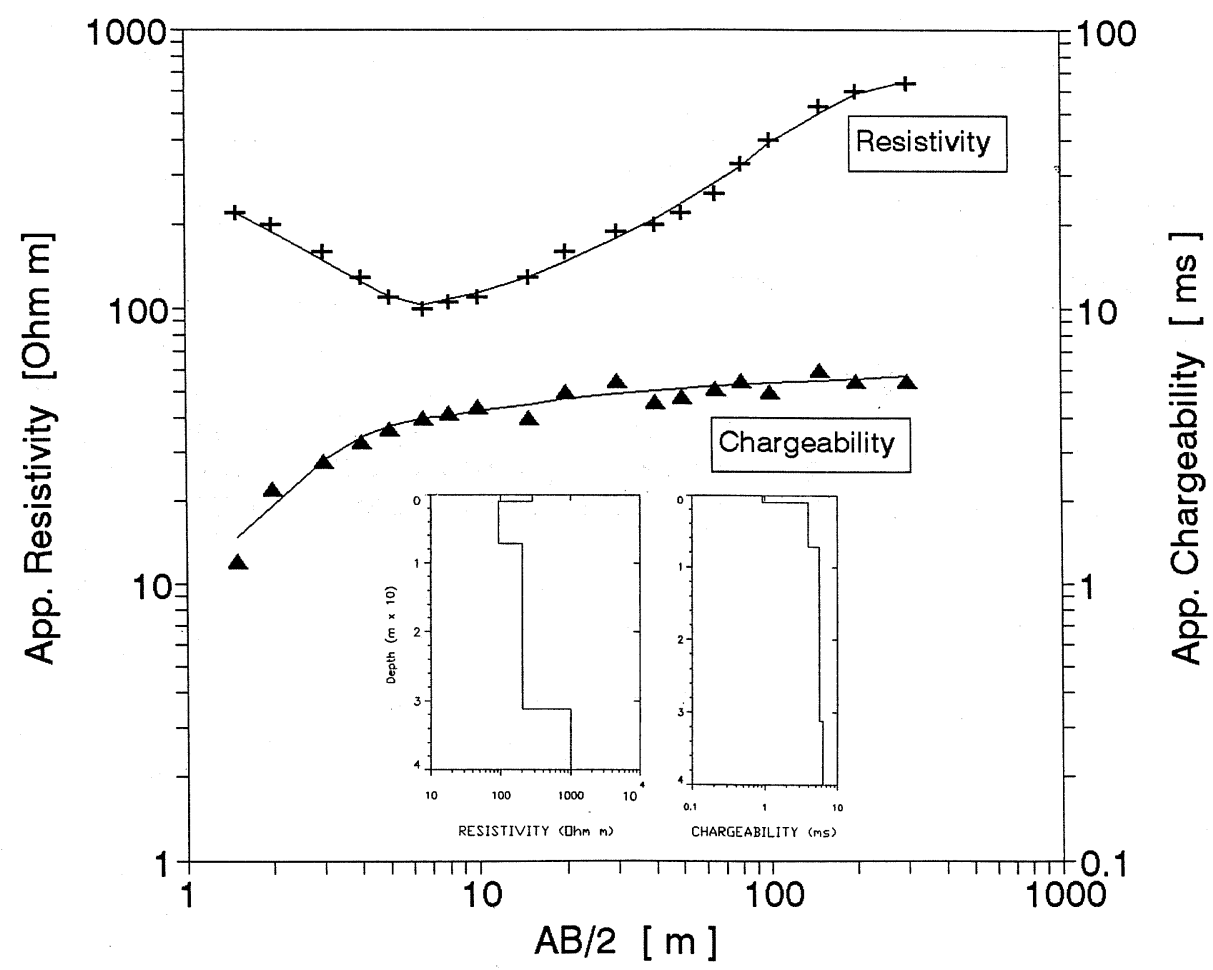

Fig. 5. Example of the resistivity and chargeability curves in the uncontaminated area (VES 12).

chargeability response was necessary, in order to obtain information on sedimentary formations over the bedrock and to distinguish between fresh water acquifers, clay and sand. The procedure disclosed a fresh water acquifer at a low depth (2-4 m). The trend of the apparent chargeability curve, without any relevant decrease also indicates that the acquifer is probably a clean sandy acquifer without any saline water intrusion.

The quantitative interpretation of the IP response has shown the existence of a layer with chargeability values in the range of $4 \div 6 \mathrm{~ms}$. The increase in chargeability is probably linked to the increase in clay material content in sandy formations. The result of sounding 12, in the uncontaminated area is plotted in fig. 5, as an example. The curves of soundings $2,3,4,6,9$, $12,14,15$ and 17 present the same behaviour as sounding 12. It is therefore possible to define the contour of the uncontaminated area, which is approximately located to the West of the line between the center of soundings 4 and 11 .

\subsection{Bi-dimensional elaboration}

The reconstruction of the vertical section along some profiles was carried out, starting from the 1-D interpretation of the soundings.

In the uncontaminated area it was possible to delineate the following stratigraphy:

- the near surface fresh acquifer with resistivity values of $100-150 \Omega \cdot \mathrm{m}$ and chargeability values, in the range of 2 and $4 \mathrm{~ms}$;

- one layer, located between the depth of 5 and $20 \mathrm{~m}(40 \Omega \cdot \mathrm{m}<\rho<50 \Omega \cdot \mathrm{m})$, characterized by chargeability values in the range of 

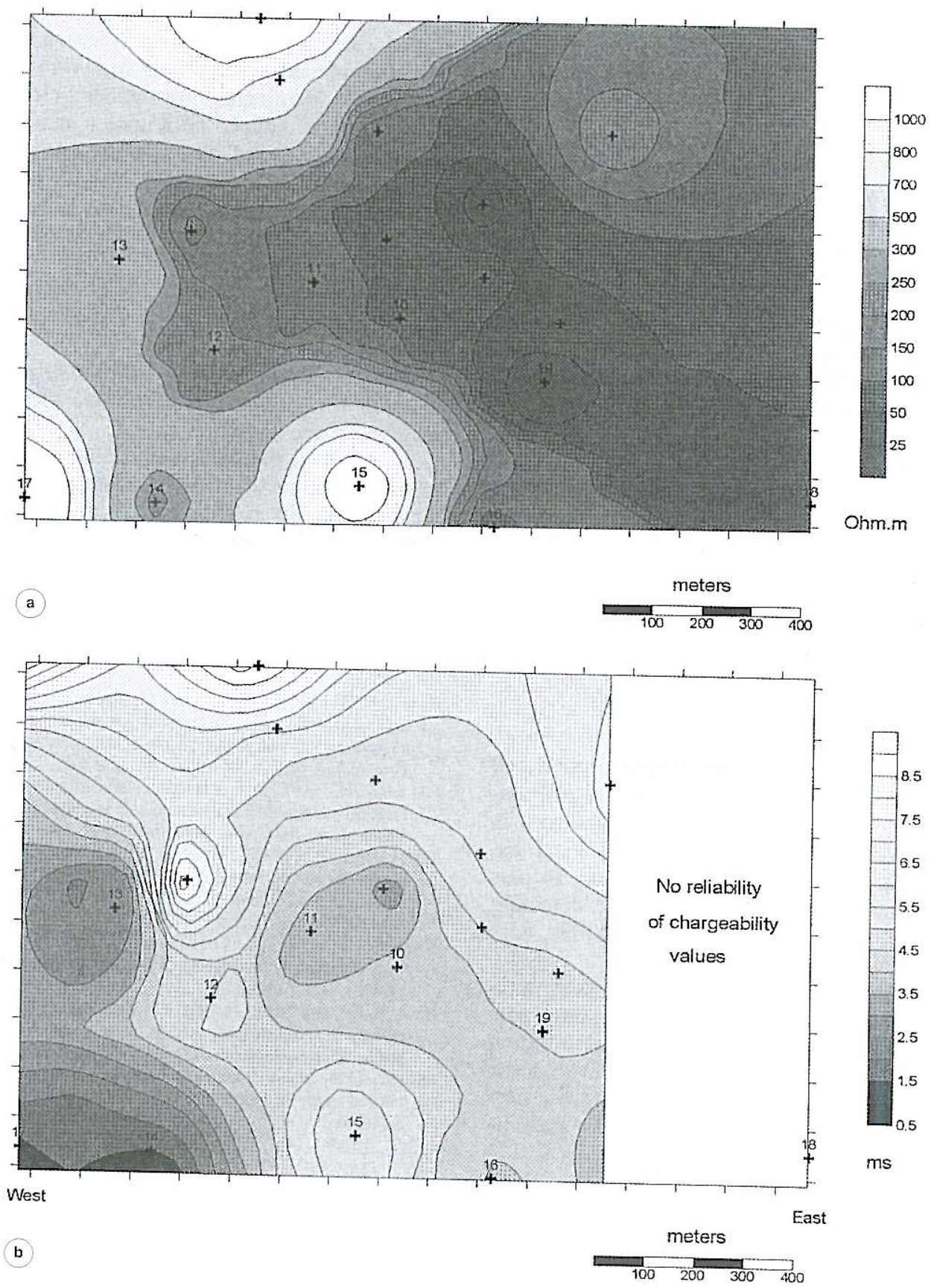

Fig. 6a,b. a) Iso-resistivity map at a depth of $15 \mathrm{~m}$; b) iso-chargeability map at a depth of $15 \mathrm{~m}$. The conductive zone (less than $100 \mathrm{Ohm} \cdot \mathrm{m}$ ) with low chargeability values delineates the salt groundwater intrusion to the South-East of the area. The blank area is the zone with no reliability of the chargeability values. 
$4 \div 6 \mathrm{~ms}$; such values can indicate the presence of clay materials in a sandy formation. The layer can also include some water saturated levels;

- the crystalline bedrock with a resistivity higher than $400 \Omega \cdot \mathrm{m}$.

A global evaluation of the results of the soundings was performed to define the hydrogeological capacity of the coastal plane. The iso-resistivity and iso-chargeability maps were plotted (fig. 6a,b), in order to detect the salt water extension in the coastal plane. The values of chargeability and resistivity corresponding to a depth of $15 \mathrm{~m}$ were chosen as they can affect the sandy formation with a high content of clay material or a possible acquifer.

The iso-resistivity and the iso-chargeability maps show an area characterized by low resistivity and chargeability values; this area represents the extension of the salt water intrusion. A small area with high resistivity and low chargeability values due to the response of the crystalline basement is located South-East of the maps.

\section{Conclusions}

The results verified the good resolution and the low cost of the survey of the joint elaboration of the IP and the resistivity soundings, in order to delineate some hydrogeological aspects of the San Priamo coastal plane. In particular, the technique is suitable for detecting the salt water intrusion in a fresh acquifer, with good reliability.

The ambiguities of the ordinary interpretation of the resistivity measurements were partially overcome thanks to the joint elaboration of resistivity and chargeability. However, some additional care was necessary during the survey to avoid electromagnetic coupling and im- prove the signal quality for higher electrode spreads. In particular, the decay curve in time domain induced polarization was very low in conductive sedimentary formations: some negative effect of induced polarization strongly affects the quality of the interpretation, especially when the soundings are carried out in the presence of salt water intrusion. However, a negative IP response seems to be diagnostic of the salt water contamination.

The geophysical survey of the San Priamo plane, using electrical methods of resistivity and chargeability:

1) defined the geometry and the type of the different formations that determine the hydrogeology of the region;

2) ascribed the presence of clay or salt water to low values of resistivity using the different chargeability response of the formations;

3 ) estimated the salt water intrusion extension along the coastal plain.

\section{REFERENCES}

BArbieri, G., G. Barrocu and G. Ranieri (1986): Hydrogeological and geophysical investigations for the evaluation of salt intrusion phenomena in Sardinia, in Proceeding of 9th SWIM, Delft, 659-670.

LAZREG, H. (1972): Application of surface resistivity methods to the delineations of salt water in Shippegan, Trans. Can. Inst. Min. Metall., 75, 32-41.

Montaldo, P. (1947): I fattori idrogeologici del Basso Flumendosa (Sarrabus) e di Bidda Maiore (Sa Picocca) Sardegna Sud Orientale, in Agricoltura Sarda, vol. 24, 1-16, 1 Tavola, 9 carte 1:100000.

NABighian, M.N. and H.M. Elliot (1976): Negative induced polarization effects from layered media, Geophysics, 41, 1236-1255.

RoY, K.K. and H.M. ElLIOT (1980): Resistivity and IP survey for delineating saline water and fresh water zones, Geoexploration, 18, 145-162.

SEIGEL, O.H. (1959): Mathematical formulation and type curves for induced polarization, Geophysics, 24, $547-565$ 